\title{
Influence of mode of storage and drying of fodder on thermophilic actinomycete aerocontamination in dairy farms of the Doubs region of France
}

\author{
J C Dalphin, D Pernet, G Reboux, J Martinez, A Dubiez, T Barale, A Depierre
}

\begin{abstract}
Airborne contamination by thermophilic actinomycetes, micromycetes and Gram negative bacteria was determined on 34 dairy farms and related to fodder drying and storage methods. Eighteen farms had a barn drying system, eight with additional heating; the remaining 16 had traditional fodder storage methods. Three air samples were obtained for each farm with a six stage Andersen sampler. The thermophilic actinomycetes were identified as Streptomyces and the dominant micromycetes as Aspergillus spp; there was no relation between the levels of these organisms. There were fewer thermophilic actinomycete colonies per Petri dish (stage 5 on the Anderson sampler) on farms with barn drying than on those with traditional storage (median (range) 7 (0$2628)$ and $56(4-2628)$ respectively). The three farms where no thermophilic actinomycetes were found had barn drying with heating and the four most modern farms had lower thermophilic actinomycete colony counts than the others (median (range) $3(0-10)$ and 48 (0-2628)). The level of thermophilic actinomycetes and, to a lesser degree, of micromycetes was higher where the farmer had farmer's lung. Thermophilic actinomycetes of the genus Streptomyces are probably the antigens associated with farmer's lung in the Doubs, and modern farms with barn drying and heating furnish some protection against this disease.
\end{abstract}

Farmer's lung is an extrinsic allergic alveolitis due to repeated exposure to mouldy plant materials. ${ }^{1}$ It is most often due to thermophilic actinomycetes, usually Micropolyspora faeni, Thermoactinomyces vulgaris, and Streptomyces spp. ${ }^{2-6}$ These organisms proliferate mainly in fodder, particularly mouldy fodder, if this is insufficiently dry when stored in a barn. Humidity is an essential factor in their proliferation $^{7}$ and the prevalence of farmer's lung is linked to rainfall, particularly during haymaking. ${ }^{89} \mathrm{~A}$ link has been found between thermophilic actinomycete concentration and risk of farmer's lung. ${ }^{510}$

The Doubs, in the Jura region, is a semimountainous, fodder producing area of France with a high prevalence of farmer's lung. ${ }^{11}$ Rainfall, especially during haymaking, is heavy ${ }^{11}$ and new techniques of fodder storage, particularly barn drying, have been developed in recent years. Fodder is brought in within a day of harvesting, spread over a grating system in the barn, and dried artificially by means of a blower taking in air from the outside. In some modern barns the ventilated area is heated to produce fodder of high nutritive quality.

The principal aim of this study was to evaluate the influence of the fodder storage method, especially barn drying, on the proliferation of thermophilic actinomycetes, other factors of farming method and modernisation being taken into account. A second aim was to give a descriptive analysis of aerial contamination by organic particles on fodder producing farms in the Doubs.

\section{Methods}

Aerial contamination by thermophilic actinomycetes, micromycetes and Gram negative bacteria was measured on 34 farms in the Doubs area, where the activity was exclusively dairying. The farms were selected because they had similar geography and climate (rainfall). The study took place in 1987 from 7 to 30 April, a time of year when cattle are still housed in sheds.

THE FARMS

Of the 34 farms 18 had a barn drying system and eight of these had drying with heating, 16 used traditional fodder storage methods, with rectangular average density bales on eight farms and high density round bales on eight farms.

Other occupational factors were determined, including whether there was a central feeding corridor, whether the barn was located at a distance from the cattle shed and whether the cattle shed had a ventilation system.

All workers employed on the 34 farms were questioned with regard to respiratory symptoms observed that same winter.

\section{MICROBIOLOGICAL ANALYSIS}

Three air samples were obtained from each farm-one from the fodder storage area before any handling of hay had taken place and two from the cattle shed, one in front of and the other behind the cows just as they began to eat.

These samples were taken in the morning between 6 and 8 am and at the same place on all farms. Two farms were studied each day, 
Table 1 Culture media, incubation temperatures, and incubation times used in Andersen samplings

\begin{tabular}{llll}
\hline Microorganisms & Medium & $\begin{array}{l}\text { Incubation } \\
\text { temperature }\left({ }^{\circ} \mathrm{C}\right)\end{array}$ & $\begin{array}{l}\text { Incubation } \\
\text { duration (days) }\end{array}$ \\
\hline Thermophilic actinomycetes & Bactoactinomycete isolation agar (DIFCO) & 44 & 7 \\
Micromycetes & Malt agar (AES) & 30 & $3-7$ \\
Gram negative bacteria & Conradi Drigalski agar & 37 & 2 \\
\hline
\end{tabular}

the first at the usual feeding time (between 6 and $7 \mathrm{am}$ ) and the second between 7 and $8 \mathrm{am}$, feeding having been delayed for an hour.

Air samples were taken at a height of one meter. The six stage Andersen sample (model 10-810, Andersen 2000 Inc, Atlanta, Georgia) was used, with a pause of 15 seconds and a flow rate of $30 \mathrm{l} / \mathrm{min}$. To limit sampling duration and to obtain each sample at the same time each day on each farm, and in the same work conditions, the method ${ }^{12}$ was adapted as follows. After sensitivity and reproducibility had been studied, and on the basis of data provided by Andersen, ${ }^{12}$ stage 5 was chosen for detection of thermophilic actinomycetes, stage 3 for micromycetes, and stage 6 for Gram negative bacteria. Plastic Petri dishes $(100 \times 15 \mathrm{~mm})$ containing $35 \mathrm{ml}$ of culture medium were used. Culture media, incubation temperatures, and incubation times are shown in table 1 . Only colonies in the hole pattern were counted and a "positive hole" correction was applied. ${ }^{12}$ Results were expressed as the mean number of colonies of microorganisms (the average of the three samples) per Petri dish. Results were related to fodder drying and storage methods and to the other occupational factors. Thermophilic actinomycetes were identified by J Lacey (Rothamsted Experimental Station, Harpenden).

\section{MEDICAL QUESTIONNAIRE}

A questionnaire based on the American
Thoracic Society questionnaire ${ }^{13}$ was used for the study of respiratory symptoms. Farmers were considered to have farmer's lung on the basis of the following definition: recurrent episodes of cough and dyspnoea without wheeze, with or without fever, with some delay in onset (4-10 hours) after contact with antigen, during the winter of 1986-7.

\section{STATISTICAL ANALYSIS}

Results are presented as medians with ranges. Distributions were compared by means of the Mann-Whitney $U$ test and the relation between thermophilic actinomycete and micromycete concentrations was analysed by linear regression.

\section{Results}

MICROBIOLOGICAL ANALYSES

The mean colony counts (average of the three samples) per Petri dish for each farm are shown in table 2 .

Thermophilic actinomycetes were found in 31 of 34 farms. There were three different strains, one being Streptomyces griseoflavus. The other two strains resembled Streptomyces but might not be previously described; they appear to be similar to Amycolata or Amycolatopsis. No colony of Micropolyspora faeni or Thermoactinomyces vulgaris was found.

A total of 34 micromycetes species were identified. With all the farms and samples

Table 2 Mean colony count of thermophilic actinomycetes, micromycetes, and Gram negative bacteria per Petri dish for each farm

\begin{tabular}{|c|c|c|c|c|c|c|c|}
\hline Farm & Actinomycetes & Micromycetes & $\begin{array}{l}\text { Gram negative } \\
\text { bacteria }\end{array}$ & Farm & Actinomycetes & Micromycetes & $\begin{array}{l}\text { Gram negative } \\
\text { bacteria }\end{array}$ \\
\hline \multicolumn{4}{|c|}{ Barn drying with heating } & \multicolumn{4}{|c|}{ Average density bales } \\
\hline $\begin{array}{l}1^{\star} \\
3^{\star} \\
4 \\
5^{\star} \\
6^{\star} \\
7 \\
8 \dagger\end{array}$ & $\begin{array}{r}0 \\
0 \\
0 \\
7 \\
7 \\
10 \\
39 \\
2628\end{array}$ & $\begin{array}{r}28 \\
20 \\
55 \\
6 \\
116 \\
46 \\
9 \\
791\end{array}$ & $\begin{array}{l}0 \\
0 \\
0 \\
0 \\
0 \\
1 \\
0 \\
0\end{array}$ & $\begin{array}{l}19 \\
20 \dagger \\
21 \\
22 \\
23 \\
24 \dagger \\
25 \\
26\end{array}$ & $\begin{array}{r}4 \\
6 \\
7 \\
52 \\
56 \\
139 \\
934 \\
2628\end{array}$ & $\begin{array}{r}1051 \\
214 \\
9 \\
29 \\
37 \\
20 \\
67 \\
39\end{array}$ & $\begin{array}{l}0 \\
1 \\
0 \\
0 \\
1 \\
0 \\
0 \\
0\end{array}$ \\
\hline Median & 7 & 37 & - & & 54 & 38 & - \\
\hline \multicolumn{4}{|c|}{ Barn drying } & \multicolumn{4}{|c|}{ Round bales } \\
\hline $\begin{array}{l}9 \dagger \\
10 \\
11 \\
12 \\
13 \\
14 \\
15 \\
16 \\
17 \\
18 \dagger\end{array}$ & $\begin{array}{r}3 \\
4 \\
5 \\
6 \\
6 \\
36 \\
42 \\
69 \\
72 \\
1759\end{array}$ & $\begin{array}{r}164 \\
80 \\
30 \\
8 \\
18 \\
4 \\
27 \\
63 \\
329 \\
47\end{array}$ & $\begin{array}{l}0 \\
1 \\
1 \\
0 \\
0 \\
1 \\
0 \\
0 \\
0 \\
0\end{array}$ & $\begin{array}{l}27 \\
28 \\
29 \\
30 \\
31 \\
32 \\
33 \\
34 \dagger\end{array}$ & $\begin{array}{r}8 \\
45 \\
54 \\
56 \\
174 \\
181 \\
249 \\
983\end{array}$ & $\begin{array}{r}12 \\
33 \\
257 \\
45 \\
28 \\
27 \\
20 \\
44\end{array}$ & $\begin{array}{l}0 \\
1 \\
0 \\
0 \\
0 \\
0 \\
1 \\
0\end{array}$ \\
\hline Median & 21 & 38 & - & & 115 & 30 & - \\
\hline
\end{tabular}

* Modern farms: barn drying with heating, a cattle shed ventilation system, a central feeding corridor, and a barn at a distance from the cattle shed.

†Farmer's lung farms. 
Table 3 Influence of fodder storage, drying methods, and other occupational factors on the number of colonies of thermophilic actinomycetes ( $A C T$ ) and micromycetes per farm

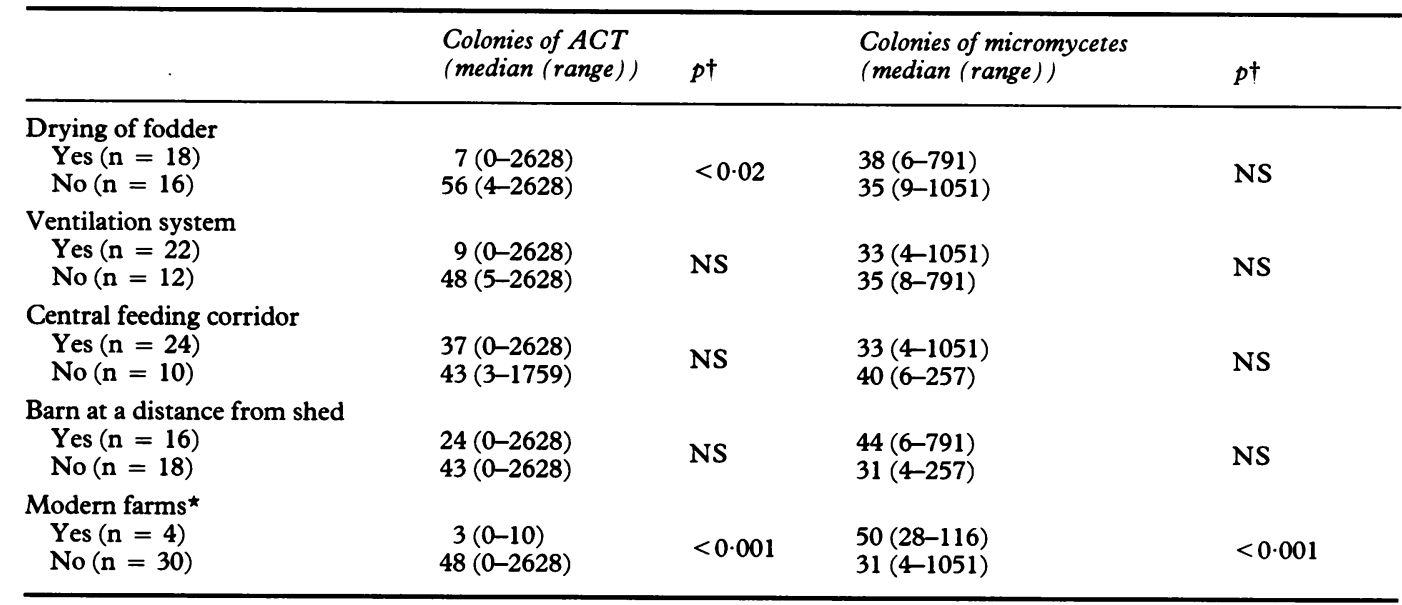

^Barn drying with heating, cattle shed ventilation system, central feeding corridor, and barn at a distance from the cattle shed. +Mann-Whitney U test.

combined, Aspergillus glaucus accounted for $40 \%$ of the identified colonies, $A$ nidulans for $23 \%$, A fumigatus for $11 \%$, Penicillium spp for $6 \%$, Mucor spp for $6 \%, A$ terreus for $5 \%$, Scopulariopsis brevicaulis for $2 \%, A$ fischeri for $1 \%$, and others for less than $1 \%$.

In decreasing order of frequency, Mucor spp were present on all the farms (in at least one of the three samples), $A$ nidulans on $29, A$ fumigatus on 28, A glaucus on 20, Scopulariopsis brevicaulis on 13, Penicillium spp on 10, $A$ terreus on five, $A$ fischeri on five, Cladosporium spp on $15 \%$, and others on less than five farms.

Gram negative bacteria were only rarely isolated (table 2). Four different species were identified: Enterobacter aglomerans (nine colonies from three samples), Escherichia coli (one colony), Klebsiella pneumoniae (one colony), Citrobacter freundi (one colony).

INFLUENCE OF OCCUPATIONAL FACTORS

There was great variation between farms in the mean thermophilic actinomycetes counts, ranging from 0 to 2628 (the maximum capacity of the Andersen sampler). A similarly wide dispersal was also found for micromycetes. There was no correlation between the mean number of thermophilic actinomycetes and micromycetes colonies $(r=0 \cdot 11)$.

There were fewer thermophilic actinomycetes on farms with barn drying than on those using the traditional storage method, [median (range)] $7(0-2628)$ and 56 (4-2628) respectively ( $\mathrm{p}<0.02$ ) (table 3 ), although the spread of results was equally wide in both groups. In the barn drying group fewer thermophilic actinomycete and micromycete colonies were found on the farms with heating (table 2), but the difference was not significant. The three farms free of thermophilic actinomycetes in all three samples had barn drying with heating and cattle shed ventilation. Seven of eight farms with drying with heating had very low thermophilic actinomycetes counts (table 2). There was no cattle shed ventilation system on the eighth farm. In the traditional storage group thermophilic actinomycete and micromycete concentrations did not differ stat- istically between farms with round bales and those with average density bales.

The influence of occupational factors on the number of thermophilic actinomycete and micromycete colonies is shown in table 3 . The cattle shed ventilation system and central feeding corridor and the distance of the storage barn from the cattle shed had no significant influence on thermophilic actinomycete and micromycete concentrations when considered individually. When all of these were present in farms that had barn drying with heating (modern farms), the concentration of thermophilic actinomycetes but not of micromycetes was significantly diminished (table 3 ). For these four modern farms the thermophilic actinomycete colony count per Petri dish was zero for farms 1 and 3, 7 for farm 5, and 10 for farm 6 .

RELATION BETWEEN ACTINOMYCETE LEVELS AND FARMERS' LUNG

The medical questionnaire completed by the farmer who had the day to day responsibility for feeding livestock during the winter of 19867. On the basis of the questionnaire six people were suspected of having farmer's lung (table 2). The thermophilic actinomycetes concentrations on the farms of these patients were higher than those on the farms of the 28 other farmers (median (range) 561 (3-2628) v 37 (0-2628); $\mathrm{p}<0.001)$. There were also more micromycetes on these six farms than on the others (189 (20-791) v 29 (4-1051); p < 0.01), though the differences were smaller. No species of micromycetes was specific to the farms associated with farmer's lung.

\section{Discussion}

In the farms we studied all thermophilic actinomycetes possibly belong to the genus Streptomyces. Only one was definitively assigned to a species (Streptomyces griseoflavus). These results differ from those of previous studies. Thermophilic actinomycetes of the genus Streptomyces are often found in fodder and are considered responsible for farmer's lung; ${ }^{10}$ the most common are Micropolyspora 
faeni and Thermoactinomyces vulgaris ${ }^{671014}$ the latter particularly in Finland. ${ }^{5}$ Streptomyces spp seem to be the dominant thermophilic actinomycetes on farms of the Doubs area, and are probably responsible for farmer's lung as our study showed a link between thermophilic actinomycete concentrations and the probability of having the disease.

Mycological analysis yielded results fairly similar to those of other reports. ${ }^{515}$ The Aspergillus genus was generally predominant and species such as Aspergillus glaucus may have a role in farmer's lung. ${ }^{5}$ In our study no species appeared specific to the farms associated with farmer's lung. There was no relation between thermophilic actinomycete and micromycete concentrations. Although thermophilic actinomycetes and micromycetes frequently cohabit, their growth temperatures are different. Possibly when fodder temperature rises slightly micromycetes dominate, whereas fermentation of fodder, with temperatures often rising to more than $40^{\circ} \mathrm{C}$, might favour the development of thermophilic actinomycetes.

Gram negative bacteria, a source of endotoxins, are found in large numbers in various agricultural locations rich in organic particles, particularly in poultry and swine rearing buildings. ${ }^{16}$ These Gram negative bacteria and their endotoxins might be responsible for the acute respiratory symptoms and chronic bronchitis observed in exposed individuals. ${ }^{17-19}$ In the exclusively fodder producing farms in our study Gram negative bacteria were very rare and chronic bronchitis among dairy farmers, which is common in the Doubs, ${ }^{20}$ is likely to have other causes.

The present study showed a lower thermophilic actinomycete count for farms with barn drying than for traditional farms. This is not surprising because fodder fermentation, which provides the high temperatures that favour thermophilic actinomycete proliferation, is linked to the humidity of the fodder at the time of storage. The difference between the barn drying and the traditional farms does not seem to us great enough to suggest that barn drying alone would provide adequate protection against farmer's lung. Of greater interest are the results obtained on farms with both barn drying and heating. This was present in the three farms totally free of thermophilic actinomycetes and seven of the eight farms with barn drying and heating had very low thermophilic actinomycete concentrations. One farm highly polluted by the microorganisms had barn drying and heating, but these had been installed in old buildings that were used before the installation (all the other farms had new buildings) and it had no cattle shed ventilation system. These findings suggest that barn drying with heating alone is not sufficient to prevent thermophilic actinomycete proliferation-or therefore farmer's lung. The modern farms, in addition to barn drying and heating, have a central feeding corridor, a barn separated from and not above the cattle shed (which is the tradition in the Doubs), and a cattle shed ventilation system. These four farms were virtually free of thermophilic actinomycetes.
We assume that there was no risk of farmer's lung on these farms, though there is little evidence to support this. Previously we were unable to show that barn drying protected against farmer's lung, ${ }^{11}$ but most of the farms we studied then, although equipped for barn drying, did not have a heating system. Traditionally, farmer's lung has been thought to be more common on small, relatively nonmechanised farms with poorly ventilated fodder storage areas. ${ }^{2122}$ Grant et al ${ }^{23}$ reported similar findings from Scotland, but also noted that the condition was not rare on large modern farms. A longitudinal study with analysis of the incidence of farmer's lung in relation to the various occupational factors considered here would seem justified.

Our study also shows that additional modern facilities are not indispensable for uncontaminated fodder. Some traditional farms had a very low concentration of thermophilic actinomycetes. On dairy farms the human factors are at least as important as the "technical" factors for the quality of fodder produced. Careful and conscientious farmers who plan haymaking with due regard to weather reports and who bring in only dry fodder will run little risk of farmer's lung, whatever techniques of drying and conditioning they use later.

We thank for their cooperation: J Lacey, Rothamsted Experimental Station, Harpenden, Hertfordshire, UK; H Allemand, department of epidemiology, Besançon, France; J Laplante, medical service of the Mutualité Sociale Agricole of the Doubs, Besançon, France; E Liegeon, department of chest diseases, Besançon, France. This work was supported by the Mutualité Sociale Agricole du Doubs, the Assurances Mutuelles Agricoles de Bourgogne-Franche-Comté, and the Conseil Général du Doubs.

1 Pepys J. Hypersensitivity diseases of the lung due to fungi and organic dusts. In: Kanos $P$, Hasck $M$, Inderleitzin TM, Miescher PA, Waksman BH, eds. Monographs in allergy. Basel: Karger, 1969:4S.

2 Pepys J, Jenkins PA, Festenstein GN, Gregory PH, Lacey ME, Skinner FA. Farmer's lung: Thermophilic actinomycetes as a source of "farmer's lung hay" antigen. Lancet 1963;ii:607-11.

3 Pepys J, Jenkins PA. Precipitin (FLH) test in farmer's lung. Thorax 1965;20:21-35.

4 Terho EO, Lacey J. Microbiological and serological studie of farmer's lung in Finland. Clin Allergy 1979;9:43-52.

5 Kotimaa MH, Husman $\mathrm{KH}$, Terho EO, Mustonen MH. Airborne molds and actinomycetes in the work environment of farmer's lung patients in Finland. Scand $J$ Work ment of farmer's lung patients
Environ Health 1984;10:115-9.

6 Festenstein GN, Gregory PH, Lacey J, Skinner FA. The microbiology of mouldy hay. Proc $R$ Soc Med 1966;59: 1007-8.

7 Festenstein GN, Lacey J, Skinner FA, Jenkins PA, Pepys J. Self-heating of hay and grain in dewar flasks and the development of farmer's lung antigens. J Gen Microbiol development of fart

8 Staines FH, Forman JAS. A survey of "farmer's lung." $J$ Coll Gen Pract 1961;4:351-82.

9 Terho EO, Heinonen OP, Lammi S. Incidence of farmer's lung leading to hospitalization and its relation to meteorological observations in Finland. Acta Med Scan 1983;213:295-8.

10 Corbaz R, Gregory PH, Lacey ME. Thermophilic and mesophilic actinomycetes in mouldy hay. J Gen Microbiol 1963;32:449-55.

11 Depierre A, Dalphin JC, Pernet D, Dubiez A, Faucompre C, Breton JL. Epidemiological study of farmer's lung in five districts of the French Doubs province. Thorax 1988 43:429-35.

12 Andersen AA. New sampler for the collection, sizing and enumeration of viable airborne particles. J Bacteriol 1958; 76:471-84

13 Ferris BG. Epidemiology standardization project. Am Rev Respir Dis 1978;118(suppl 7-55).

14 Gregory PH, Festenstein GN, Lacey ME, Skinner FA, Pepys J, Jenkins PA. Farmer's lung disease: the development of antigens in moulding hay. J Gen Microbiol 1964;36:429-39. 
15 Gregory PH, Lacey ME. Mycological examination of dust from mouldy hay associated with farmer's lung disease. $J$ Gen Microbiol 1963;30:75-88.

16 Clark S, Rylander R, Larsson L. Airborne bacteria, endotoxin and fungi in dust in poultry and swine confinement buildings. Am Ind Hyg Ass J 1983;44:537-41.

17 Donham KJ, Haglind P, Peterson Y, Rylander R. Environmental and health studies in swine confinement buildings. Am J Ind Med 1986;10:289-93.

18 Kennedy SM, Christiani DC, Eisen EA, Wegman DH, Greaves IA, Olenchock SA, et al. Cotton dust and endotoxin exposure-response relationships in cotton textile workers. Am Rev Respir Dis 1987;135:194-200.

19 Venaille T, Snella MC, Holt PG, Rylander R. Cell recruit- ment into lung wall and airways of conventional and pathogen-free guinea pigs after inhalation of endotoxin Am Rev Respir Dis 1989;139:1356-60.

20 Dalphin JC, Bildstein F, Pernet D, Dubiez A, Depierre A

Prevalence of chronic bronchitis and respiratory function in a group of dairy farmers in the French Doubs province. in a group of dairy farm

21 Watkins-Pitchford. Farmer's lung: a review. $\mathrm{Br} J$ Ind Med 1966;23:16-23.

22 Dyer EL. Farmer's lung: Industrial hazard for rural inhabitants. South Med J 1980;73:353-64.

23 Grant IWB, Blyth W, Wardrop VE, Gordon RM, Pearson JCG, Mair A. Prevalence of farmer's lung in Scotland: a pilot survey. BMJ 1972;1:530-4. 